\title{
Equisetum hyemale: a new candidate for green corrosion inhibitor family
}

\author{
N. Karki, ${ }^{1,2}$ S. Neupane, ${ }^{1}{ }^{10} *$ Y. Chaudhary, ${ }^{1}$ D.K. Gupta ${ }^{1,3}$ \\ and A.P. Yadav 1 (iD) \\ ${ }^{1}$ Central Department of Chemistry, Tribhuvan University, 44613, Kathmandu, Nepal \\ ${ }^{2}$ Bhaktapur Multiple Campus, Tribhuvan University, 44800, Bhaktapur, Nepal \\ ${ }^{3}$ Tri-Chandra Multiple Campus, Tribhuvan University, 44605, Ghantaghar, Kathmandu, \\ Nepal \\ *E-mail: amar2y@yahoo.com, shova_n@yahoo.com
}

\begin{abstract}
Plant extracts are a possible better alternative source of eco-friendly corrosion inhibitors for metallic materials. Herein, methanol extract of Equisetum hyemale (EHE) has been studied as an eco-friendly inhibitor for the corrosion protection of mild steel (MS) in $1.0 \mathrm{M} \mathrm{H}_{2} \mathrm{SO}_{4}$. The corrosion inhibition effects of Equisetum hyemale were evaluated by weight loss, potentiodynamic polarization, electrochemical impedance spectroscopy (EIS), and surface analyses. The weight loss results divulged a decrease in corrosion inhibition efficiency (IE) with temperature. Moreover, IE increased until six hours of immersion, then decreased afterward. Similarly, EIS studies showed an increase in charge transfer resistance together with a decrease in double-layer capacitance. The current density decreased with an increment of the inhibitor concentration without affecting the reaction mechanism. Surface characterization indicated the surface coverage of the MS by the phytochemicals present in the EHE. Thermodynamic parameters such as free energy, enthalpy, entropy of adsorption, and activation energy calculations supported a mixed type of adsorption involving both physical and chemical interactions. The molecular adsorption of the phytochemicals showed a spontaneous and consistent behavior with the Langmuir adsorption isotherm model.
\end{abstract}

Keywords: Equisetum hyemale, eco-friendly inhibitor, weight loss, potentiodynamic polarization, electrochemical impedance spectroscopy (EIS).

Received: December 24, 2020. Published: February 10, 2021 doi: $\underline{10.17675 / 2305-6894-2021-10-1-12}$

\section{Introduction}

Corrosion is a universal phenomenon responsible for the losses and failures of the structural materials. The economic losses due to corrosion account for 3-4\% of GDP, of which 30$40 \%$ can be saved with proper use of corrosion expertise [1]. The metallic corrosion due to the use of acid for removing rust, scales, or chalky deposits from mild steel is a common problem in industrial process such as acid pickling, cleaning of boilers, oil well acidizing, etc. [2-5]. The corrosive acid solution starts to attacks at the defect or at the kink part of the 
surface causing enormous a significant loss of material properties leading to failure [6]. Therefore, corrosion protection of such metallic materials from acidic atmosphere is an essential step in mitigating the corrosion loss. The use of inhibitors for mitigating corrosion of materials used in acid solution are well practiced with different levels of success [7]. Inhibitor molecules retard the rate of corrosion due to their adsorption on the metal surface, and even a small amount of inhibitor significantly suppress the rate of corrosion [8].

The factors that can define the efficiency of inhibitors are stability of formed chelate, type of corrosion medium, possible steric effects, availability of lone pairs/ $\pi$-electrons, aromaticity, type of hetero elements, and interaction between $p$-orbital of inhibitor to $d$ orbital of metal [9-14]. Most effective and efficient inhibitors are natural or synthetic organic compounds [15-25], and inorganic compounds like chromate, dichromate, arsenate, etc. [26, 27]. Nevertheless, the environmental concerns have limited the use of these effective industrial inhibitors [28, 29]. Increasing environmental legislation and ecological awareness motivates researchers to develop eco-friendly, non-toxic, and readily available inhibitor adopting green methods [20, 22].

Natural products like essential oil from plants or crude plant extracts have been extensively studied and promoted as alternative inhibitors. These plant extracts are the rich source of naturally synthesized organic compounds, which are biodegradable, renewable, and can be extracted with low cost adopting green methods. They contain complex organic species such as alkaloids, flavonoids, polyphenol, tannins, nitrogen bases, carbohydrates, and protein as well as hydrolysis products in their composition [25]. These compounds contain heteroatoms such as nitrogen $(\mathrm{N})$, oxygen $(\mathrm{O})$, sulfur $(\mathrm{S})$ having high electron negativity, which forms double or triple bonds in their structure with available lone pair of electrons [21]. Therefore, they have a high tendency for adsorption on the metal surface, and hence they function as a corrosion inhibitor [30-32]. Adsorption of inhibitor molecules block the active sites on the metal surface and reduce the corrosion by affecting cathodic and/or anodic reactions. Such a phenomenon also affects the ingress of aggressive species to the metal surface and alters the electrical resistance of the metal surface [33]. The different functional groups present in the extract can produce a synergistic effect in enhancing the inhibition efficiency (IE) [34].

There is no dearth of research reports on the plant extracts as effective corrosion inhibitors such as Eichhornia Crassipes [3], Curcuma Longa [7], Henna [13, 26], Moringa Oleifera [19], Aloes [24], Coconut [27], Chenopodium Ambrosioides [28], Ginko [29], Watermelon [30], Zallouh [31]. Nepal is blessed with large varieties of endemic high altitude plants [32]. Extract of these plants have potent to be corrosion inhibitor. There is on-going research on screening of the high-altitude plants of Nepal as a possible good source of corrosion inhibitors. The corrosion test results have shown the extract of Artemisia vulgaris [33], Lanata camara [34], Euphorbia royleana [35], Pogostemon benghalesis [36, 37], Gaultheria fragrantisima [38], Berberis aristata [39] as a good inhibitor for corrosion of mild steel (MS) in an acidic environment. The IE of these plant extracts for corrosion 
protection of MS have been over 95\%. The present work reports on the corrosion inhibition efficiency of the plant Equisetum hyemale (phylum: Sphenophyta, family: Equisetaceae, and common name: horsetail), which is one of the perennial herbs [40]. Phytochemical screening of alcoholic extract of aerial parts of the plants has shown the presence of phytochemicals like rutin, 2-(sophorosyl)-1-(4-hydroxyphenyl)ethanone, $\alpha$ - $D$-fructofuranose, $L$-uridine, quercetin, 5-hydroxymethylfurfural, containing some falvonol, and phenyl glycosides [4143]. Figure 1 shows the molecular structure of these compounds. These plant extracts have not yet been tested for corrosion inhibition properties, and therefore, it is a pristine plant extract for corrosion study. This study was undertaken to evaluate the methanolic extract of Equisetum hyemale as an eco-friendly corrosion inhibitor for MS in $1.0 \mathrm{M} \mathrm{H}_{2} \mathrm{SO}_{4}$. The IE of the extract was determined using weight loss, potentiodynamic polarization, electrochemical impedance spectroscopy (EIS), and surface analyses. Effect of temperature on IE and corresponding thermodynamics parameters were used to evaluate the adsorption phenomenon.<smiles>O=c1ccn(C2OC(CO)C(O)C2O)c(=O)[nH]1</smiles>

L-Uridine<smiles>[R10]c1ccc(-c2oc3cc(O)cc(O)c3c(=O)c2O[C@@H]2O[C@H](CO[C@H]3O[C@H](C)[C@@H](O)[C@H](O)[C@H]3O)[C@@H](O)[C@H](O)[C@H]2O)cc1O</smiles><smiles>O=c1c(O)c(-c2ccc(O)c(O)c2)oc2cc(O)cc(O)c12</smiles><smiles>OCC1OC(O)(CO)C(O)C1O</smiles>

a-D-fructofuranose<smiles>O=Cc1ccc(CO)o1</smiles>

5-hydroxymethylfurfural

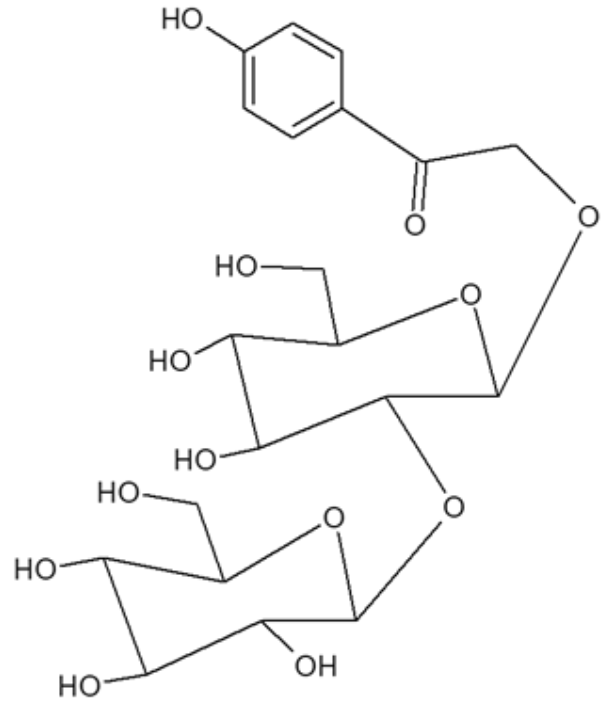

2-(sophorosyl)-1-(4-hydroxyphenyl) ethanone

Figure 1. Structure of various compounds isolated from the alcoholic extract of Equisetum hyemale [41-43]. 


\section{Experimental}

\subsection{Preparation of $M S$ samples}

MS samples were cut from a flat sheet collected from the local market of Nepal. The coupons of dimensions $3.25 \times 3.25 \times 0.15 \mathrm{~cm}$ were design for weight loss measurements whereas $2.0 \times 2.0 \times 0.15 \mathrm{~cm}$ size coupons with the exposed surface area of $0.608 \mathrm{~cm}^{2}$ was used for electrochemical measurements. The coupons were abraded with silicon carbide ( $\mathrm{SiC}$ ) paper till \#1200 grits. The abraded samples were cleaned ultrasonically in ethanol for 15 min for the removal of residual particles, washed with ethanol, and dried with compressed air.

\subsection{Equisetum hyemale extract and inhibitor solution preparation}

Aerial part of Equisetum hyemale, collected from Gundu (latitude: 27³9'2.5"N, longitude: $85^{\circ} 24^{\prime} 59.6^{\prime \prime} \mathrm{E}$ and altitude: $1402 \mathrm{~m}$ ), Bhaktapur, Nepal, was dried in the shade and pulverized into a fine powder. $200 \mathrm{~g}$ of powder was soaked in $1000 \mathrm{~mL}$ methanol for $72 \mathrm{~h}$ with occasional shaking followed by filtration. The process was repeated until colorless effluent was obtained. Then, the collected filtrate was initially concentrated using IKA RV 10 digital rotary evaporator. It was further dried on a water bath to get a solid residue named as Equisetum hyemale extract (EHE). $1.0 \mathrm{gm}$ of EHE was dissolved in $1000 \mathrm{~mL}$ warm $1.0 \mathrm{M} \mathrm{H}_{2} \mathrm{SO}_{4}$. Undissolved extract residue was removed by filtration using standard filter paper. The filtrate constituted an $E H E$ stock solution of $1000 \mathrm{ppm}$. It was further diluted to $800,600,400$, and $200 \mathrm{ppm}$ using $1.0 \mathrm{M} \mathrm{H}_{2} \mathrm{SO}_{4}$. All chemicals were of reagent grade, and laboratory-grade solvents were procured from Fisher Scientific, India.

\subsection{FTIR analysis of EHE}

The presence of different functional groups in $E H E$ was confirmed by making Fourier transform infrared (FTIR) analysis in attenuated total reflectance (ATR) mode using a Shimadzu FTIR spectrophotometer.

\subsection{Electrochemical Measurements}

A Gamry reference 600 potentiostat running on Gamry framework software was used to perform electrochemical measurements. Measurements were carried out in a $300 \mathrm{~mL}$ test solution using a three-electrode cylindrical glass cell. The MS sample was used as a working electrode, a saturated calomel electrode (SCE) as a reference electrode and a platinum wire as an auxiliary electrode. All the potential mentioned in this paper are referred to as SCE. Before each electrochemical measurement, the MS sample was immersed in the test solution for $20 \mathrm{~min}$ to attain a steady-state open circuit potential (OCP). Potentiodynamic polarization was carried out in the range of $\pm 0.3 \mathrm{~V}$ from OCP with a scan rate of $0.5 \mathrm{mV} / \mathrm{s}$, and the polarization started from a cathodic limit to anodic limit. The corrosion potential $\left(E_{\text {corr }}\right)$, corrosion current $\left(I_{\text {corr }}\right)$, and Tafel slopes were estimated to evaluate the $I E$ of the $E H E$ on MS corrosion in $1.0 \mathrm{M} \mathrm{H}_{2} \mathrm{SO}_{4}$. The $I E$ was calculated by the equation (1) [13]. 


$$
I E \%=\frac{I_{\text {corr }}^{0}-I_{\text {corr }}}{I_{\text {corr }}^{0}} \times 100 \%
$$

Where $I_{\text {corr }}$ and $I_{\text {corr }}^{0}$ represent corrosion current densities with and without inhibitor, respectively.

EIS was used to measure the AC response of the MS in $1.0 \mathrm{M} \mathrm{H}_{2} \mathrm{SO}_{4}$ containing $E H E$ of varying concentrations. A superimposing sine wave signal of $10 \mathrm{mV}$ peak to peak at frequencies between $100 \mathrm{kHz}$ to $0.01 \mathrm{~Hz}$ was applied at OCP. The response of the AC signal in terms of charge transfer resistance $\left(R_{\mathrm{ct}}\right)$ and double layer capacitance was analyzed by fitting the response with the help of an equivalent circuit. The $R_{\mathrm{ct}}$ value thus obtained was used to estimate the $I E$ by the equation 2 [13]:

$$
I E \%=\frac{R_{\mathrm{ct}}-R_{\mathrm{ct}}^{0}}{R_{\mathrm{ct}}} \times 100 \%
$$

Where $R_{\mathrm{ct}}$ and $R_{\mathrm{ct}}^{0}$ are charge transfer resistances with and without inhibitor, respectively.

\subsection{Weight loss measurements}

The weight loss measurements were used to evaluate the performance of the inhibitor, and the nature of adsorption isotherms. Two measurements were performed in a row. On the one hand, pre-weighed MS samples were immersed in $100 \mathrm{~mL} 1.0 \mathrm{M} \mathrm{H}_{2} \mathrm{SO}_{4}$ and $1.0 \mathrm{M} \mathrm{H}_{2} \mathrm{SO}_{4}+E H E$ for different time intervals of 3, 6, 9, 12, and $24 \mathrm{~h}$. A $1000 \mathrm{ppm} E H E$ solution at RT was used as an inhibitor. The MS samples were taken out, washed thoroughly with distilled water, dried, preserved in a desiccator overnight, and weighed again. On the other hand, a series of samples immersed in 1000, 800, 600, 400, and $200 \mathrm{ppm} E H E$ at RT for $6 \mathrm{~h}$ to observe the effect of the $E H E$ concentration. Similarly, the effect of temperature on $I E$ and thermodynamic parameters were estimated by performing measurements at $298 \mathrm{~K}$, $308 \mathrm{~K}, 318 \mathrm{~K}, 328 \mathrm{~K}$, and $338 \mathrm{~K}$ using $1000 \mathrm{ppm} E H E$. The immersion time was $6 \mathrm{~h}$, and the temperature was adjusted by using a Clifton water bath (model no. NE2-4D).

From the above experimental setup, corrosion rate $(C R)$, surface coverage $(\theta)$, and inhibition efficiency $(I E \%)$ determined using equations 3, 4, and 5 [24].

$$
C R=\frac{87.6 \mathrm{~W}}{A t D}
$$

Where $W$ is weight loss ( $\mathrm{mg}$ ) of MS sample, $A$ is surface area $\left(\mathrm{cm}^{2}\right)$ of the coupon, $t$ is time (hours) of immersion, and $D$ is density $(\mathrm{g} / \mathrm{mL})$ of MS. From the weight loss data, the geometric surface coverage $(\theta)$ of MS due to blocking action of the inhibitor can be expressed as:

$$
\theta=\frac{W_{1}-W_{2}}{W_{1}}
$$


Where, $W_{l}$ and $W_{2}$ are the weight loss in the absence and presence of inhibitor, respectively. The inhibition efficiency can then be estimated as:

$$
I E \%=\left(\frac{W_{1}-W_{2}}{W_{1}}\right) \times 100
$$

All the measurements were made in triplicate to assure the reproducibility of the results, and illustrated data are the mean values of three measurements.

\subsection{Surface analysis}

Scanning electron microscope (SEM, Bio-Logic M470 Ac-SECM) in conjugation with an energy dispersive spectrometer (EDX, accelerating voltage $15 \mathrm{kV}$ ) was used for surface study of MS surface under different experimental conditions. The MS samples were immersed in the EHE solutions of $400 \mathrm{ppm}$ and $1000 \mathrm{ppm}$ for $24 \mathrm{~h}$ to make the surface characterization. The SEM images of the MS samples were taken at several locations to ensure reproducibility. Similarly, EDX analysis was carried out for elemental information.

\section{Results and Discussion}

\subsection{FTIR analysis of EHE}

Figure 2 shows an ATR mode FTIR spectrum of crude $E H E$. The various adsorption peaks are indicative of the presence of different bonds and functional groups in the EHE. Broad peaks at 3367 to $3232 \mathrm{~cm}^{-1}$ are representative of the $\mathrm{O}-\mathrm{H}$ group. A peak at 2935 is due to $\mathrm{C}-\mathrm{H}$ stretching of alkane. The peak confirms the presence of $\mathrm{C}=\mathrm{O}$ of amine and carboxylic acid at $1635 \mathrm{~cm}^{-1}$. Similarly, peaks at 1570 and $1400 \mathrm{~cm}^{-1}$ are due to the presence of the $\mathrm{C}=\mathrm{C}$ bond. The peaks at 1570 and $1400 \mathrm{~cm}^{-1}$ attributed to $\mathrm{N}-\mathrm{H}$ and $\mathrm{C}-\mathrm{O}-\mathrm{H}$ bending, respectively. Another peak at $1292 \mathrm{~cm}^{-1}$ indicates the $\mathrm{C}-\mathrm{O}$ stretching of ether, alcohol, or carboxylic acid. The $\mathrm{C}-\mathrm{O}$ of polysaccharide and $\mathrm{C}-\mathrm{N}$ stretching confirmed by the presence of a peak at $1026 \mathrm{~cm}^{-1}$. FTIR result shows that the main constituents of plant extract contained an aromatic ring, oxygen, and nitrogen atoms as main constituents. Phytochemical studies of Equisetum hyemale have reported the presence of similar FTIR bands [41-43]. The presence of such functionality is a prerequisite for typical corrosion inhibitors [25]. Therefore, its effect on corrosion inhibition of MS in acidic medium has to be clarified [27].

\subsection{Electrochemical measurements}

OCP variation of MS samples recorded in the presence of $E H E$ extract of different concentrations in $1.0 \mathrm{M} \mathrm{H}_{2} \mathrm{SO}_{4}$ solution with its bare counterpart is shown in Figure 3a. The result shows an increment of OCP in the beginning and attaining a steady potential after 15 min. The addition of $E H E$ shifted the OCP towards positive value compared to $1.0 \mathrm{M}$ $\mathrm{H}_{2} \mathrm{SO}_{4}$ solution without $E H E$. However, the shift in OCP is less than $10 \mathrm{mV}$, which proves 
that the EHE acts as a mixed type of inhibitor [14]. The positive shift of OCP indicated the formation of an adsorb layer of $E H E$ on the MS surface [44].

The inhibition effect of $E H E$ was further studied by potentiodynamic polarization of MS samples in $1.0 \mathrm{M} \mathrm{H}_{2} \mathrm{SO}_{4}$ and $1.0 \mathrm{M} \mathrm{H}_{2} \mathrm{SO}_{4}+E H E$ of different concentrations. Figure $3 \mathrm{~b}$ represents the polarization curves in various concentrations of $E H E$. The values of corrosion current $\left(I_{\text {corr }}\right)$ and corrosion potential $\left(E_{\text {corr }}\right)$ were used to interpret the effect of $E H E$ on inhibition of the MS corrosion in acidic solution. Table 1 summarizes the $I_{\text {corr }}^{0}, E_{\text {corr }}^{0}$, and $I E$ values estimated form the polarization curves for various concentrations of $E H E$.

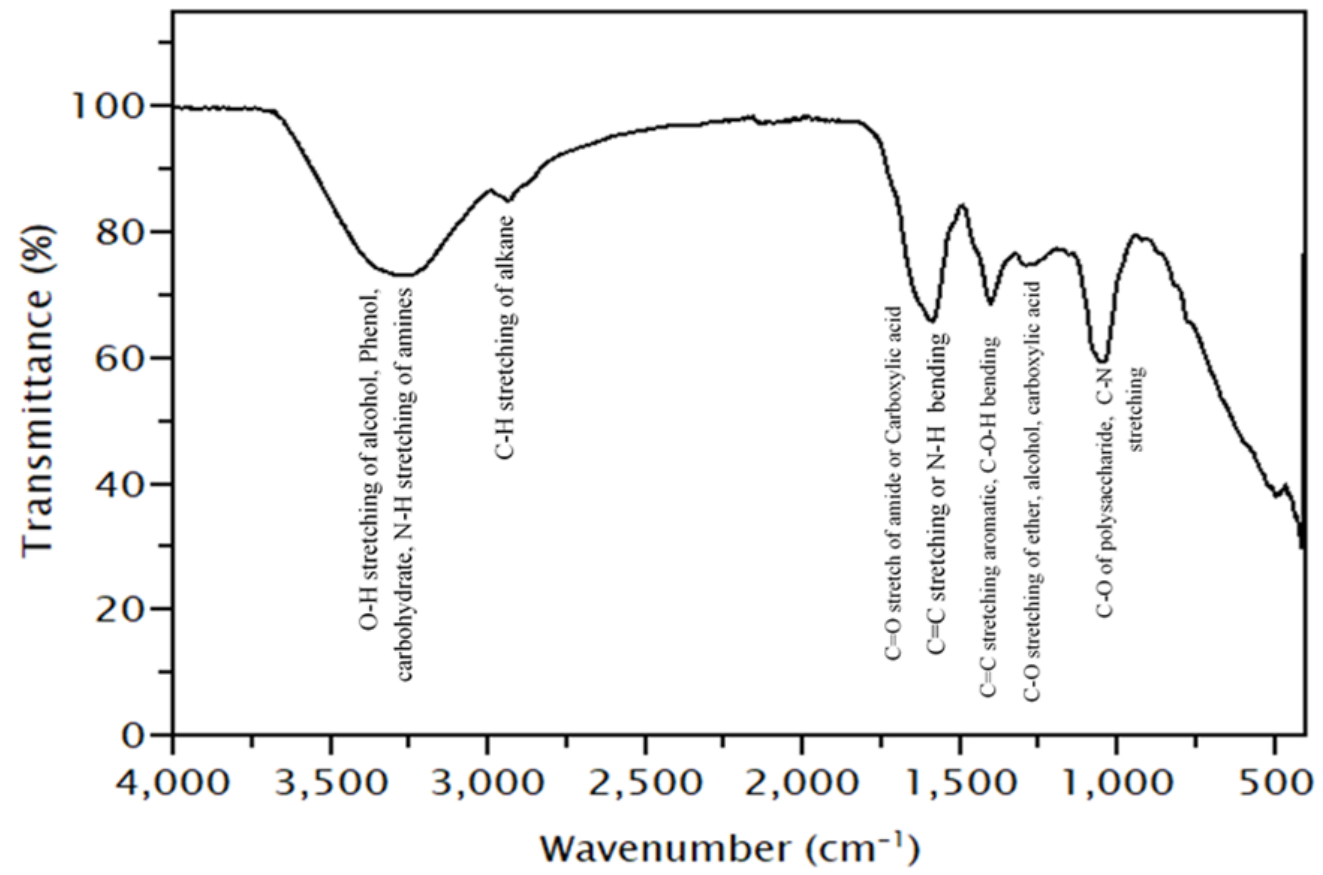

Figure 2. FTIR spectra of methanol extract of Equisetum hyemale (EHE).

Table 1. Potentiodynamic polarization parameters for the corrosion of MS samples at various EHE concentrations.

\begin{tabular}{cccc}
\hline Concentration $(\mathbf{p p m})$ & $-\boldsymbol{E}_{\text {corr }}(\mathbf{V} / \mathbf{S C E})$ & $\boldsymbol{I}_{\text {corr }}\left(\mathbf{A} / \mathbf{c m}^{\mathbf{2}}\right)$ & $\boldsymbol{I E \%}$ \\
\hline Blank & 0.428 & $1.93 \times 10^{-3}$ & - \\
200 & 0.432 & $5.47 \times 10^{-4}$ & 71.77 \\
400 & 0.432 & $4.41 \times 10^{-4}$ & 77.21 \\
600 & 0.432 & $2.05 \times 10^{-4}$ & 89.38 \\
800 & 0.426 & $1.49 \times 10^{-4}$ & 92.29 \\
1000 & 0.428 & $1.40 \times 10^{-4}$ & 92.74 \\
\hline
\end{tabular}


The addition of $1000 \mathrm{ppm}$ of $E H E$ inhibitor has resulted in significantly suppressing the corrosion current by about 14 times. This confirms the fact that $E H E$ has worked as a suitable inhibitor for the protection of MS. The addition of $E H E$ has mainly suppressed the cathodic current, and a marginal increase of slope with the concentration of inhibitor is found. Therefore, the cathodic reduction of hydrogen is suppressed by merely blocking the MS surface by organic molecules present in the EHE [45]. Shift in value of $E_{\text {corr }}$ is almost negligible, which reveals that $E H E$ worked as a mixed type of inhibitor [14]. The calculation shows that the $I E$ increases with the concentration of $E H E$ in acid solution, reaching a value of approximately $93.0 \%$ at $1000 \mathrm{ppm}$. Adsorption phenomenon ascribed to the synergistic effect of different organic molecules with different functionalities facilitating the formation of an inhibiting film [6].
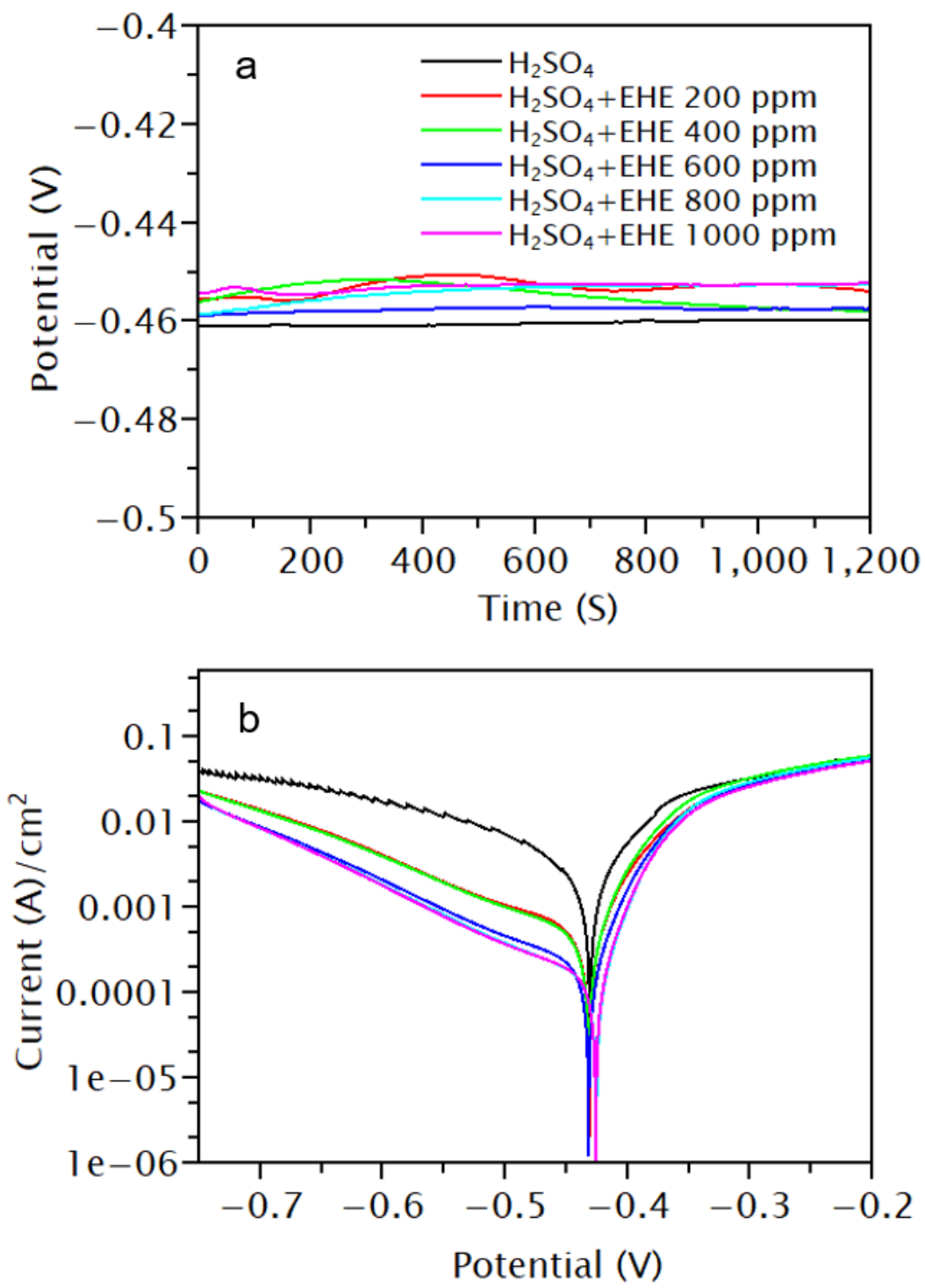

Figure 3. a. Variation of OCP of MS sample with different $E H E$ concentrations; b. Polarization curve of mild steel in $1.0 \mathrm{M} \mathrm{H}_{2} \mathrm{SO}_{4}+E H E$ of different concentrations. 
The effect of $E H E$ was further studied at steady-state conditions by impedance measurements of the $\mathrm{MS}$ in $1.0 \mathrm{M} \mathrm{H}_{2} \mathrm{SO}_{4}+E H E$ of different concentrations at OCP. Figure $4 \mathrm{a}, 4 \mathrm{~b}$, and $4 \mathrm{c}$ represent the Nyquist, Bode modulus, and phase plots, respectively. Here the symbols represent the measured data, and solid lines represent the fitting data using Z-view software (V3.2b). A simple Randles circuit consisting of a one-time constant is used to fit the impedance spectra, as shown in Figure $4 \mathrm{~d}$. The $R_{\mathrm{s}}, R_{\mathrm{ct}}$, and $C P E$ represent the solution resistance, charge transfer resistance, and constant phase element, respectively. The fitted parameters, along with $I E$, are tabulated in Table 2. Several publications have explained the use of $C P E$ for depressed semicircle by taking into account the surface inhomogeneity and related relaxation process [5, 17, 28, 29, 46-53]. The impedance function of $C P E$ is represented by the expression 6 [24]:

$$
Z_{C P E}=\frac{1}{\mathrm{Q}(j \omega)^{n}}
$$

Where $\mathrm{Q}$ represents the magnitude of the $C P E, j$, the imaginary number $\left(j^{2}=-1\right), \omega$, being angular frequency $(\omega=2 \pi f)$, and $n$, the $C P E$ exponent $(-1 \leq n \leq+1)$, whose value is used to gauge the non-homogeneity or roughness of the surface [47]. At $n=0$, the $C P E$ represents a pure resistor; at $n=-1$, an inductor; and at $n=+1$, a pure capacitor [48].

Table 2. Impedance parameters for corrosion of mild steel in $1.0 \mathrm{M} \mathrm{H}_{2} \mathrm{SO}_{4}$ at various $E H E$ concentrations.

\begin{tabular}{|c|c|c|c|c|c|}
\hline $\begin{array}{c}\text { Concentration } \\
(\mathbf{p p m})\end{array}$ & $R_{\mathrm{s}}\left(\Omega \mathrm{cm}^{2}\right)$ & $C P E\left(\mathrm{~F} \mathrm{~s}^{(1-a)} \mathrm{cm}^{-2}\right)$ & $n$ & $R_{\mathrm{ct}}\left(\Omega \mathrm{cm}^{2}\right)$ & $I E \%$ \\
\hline Blank (0) & 3.26 & 180.81 & 0.878 & 7.29 & - \\
\hline 200 & 3.527 & 104.36 & 0.865 & 22.31 & 67.32 \\
\hline 400 & 3.06 & 112.50 & 0.843 & 25.11 & 70.97 \\
\hline 600 & 2.89 & 81.10 & 0.845 & 42.9 & 83.01 \\
\hline 800 & 3.099 & 78.49 & 0.849 & 44.22 & 83.51 \\
\hline 1000 & 3.161 & 52.54 & 0.882 & 53.15 & 86.28 \\
\hline
\end{tabular}

Nyquist plot showing a single depressed capacitive loop at high frequency is indicative of a single charge transfer process of Fe-dissolution. The Nyquist curve shape remains the same with the addition of $E H E$, which implies that the addition of $E H E$ does not change the MS corrosion mechanism in $1.0 \mathrm{M} \mathrm{H}_{2} \mathrm{SO}_{4}$. Nevertheless, the diameter of the capacitive loops increases with the concentration of $E H E$. Therefore, inhibition effect increases with the concentration of the $E H E$. The increment of the inductive loop observed in the lower frequency with the concentration of $E H E$ might be attributed to the relaxation phenomenon of adsorbed intermediates such as sulfate ions $\mathrm{Fe}\left(\mathrm{SO}_{4}^{2-}\right.$ ads $)$ and inhibitor molecules $[49,54]$. 
The increment of phase angle in a Bode-phase plot $[55,56]$ and the value of impedance at low frequencies in the Bode-modulus plot [46] with the concentration of $E H E$ also confirm the inhibitive behavior of $E H E$ with its concentration. The increase of phase angle with the concentration of inhibitor is presumably due to more coverage of the MS surface by inhibitor molecules. A similar behavior is reported elsewhere [15, 57, 58].

The fitting results show a decrease in $C P E$ with the concentration of $E H E$, indicating that the adsorption of inhibitor molecules results in decreasing the dielectric constant of the double layer. It may also be attributed to an increase in the thickness of the electric double layer due to the large size of inhibitor molecules compared to water dipole, which is substituted in the adsorption process. It is noteworthy that inhibitor molecules have a larger size compared to water dipole [59]. The gradual replacement of water dipoles by the inhibitor molecules on the metal surface suppressed the rate of metal dissolution [60].
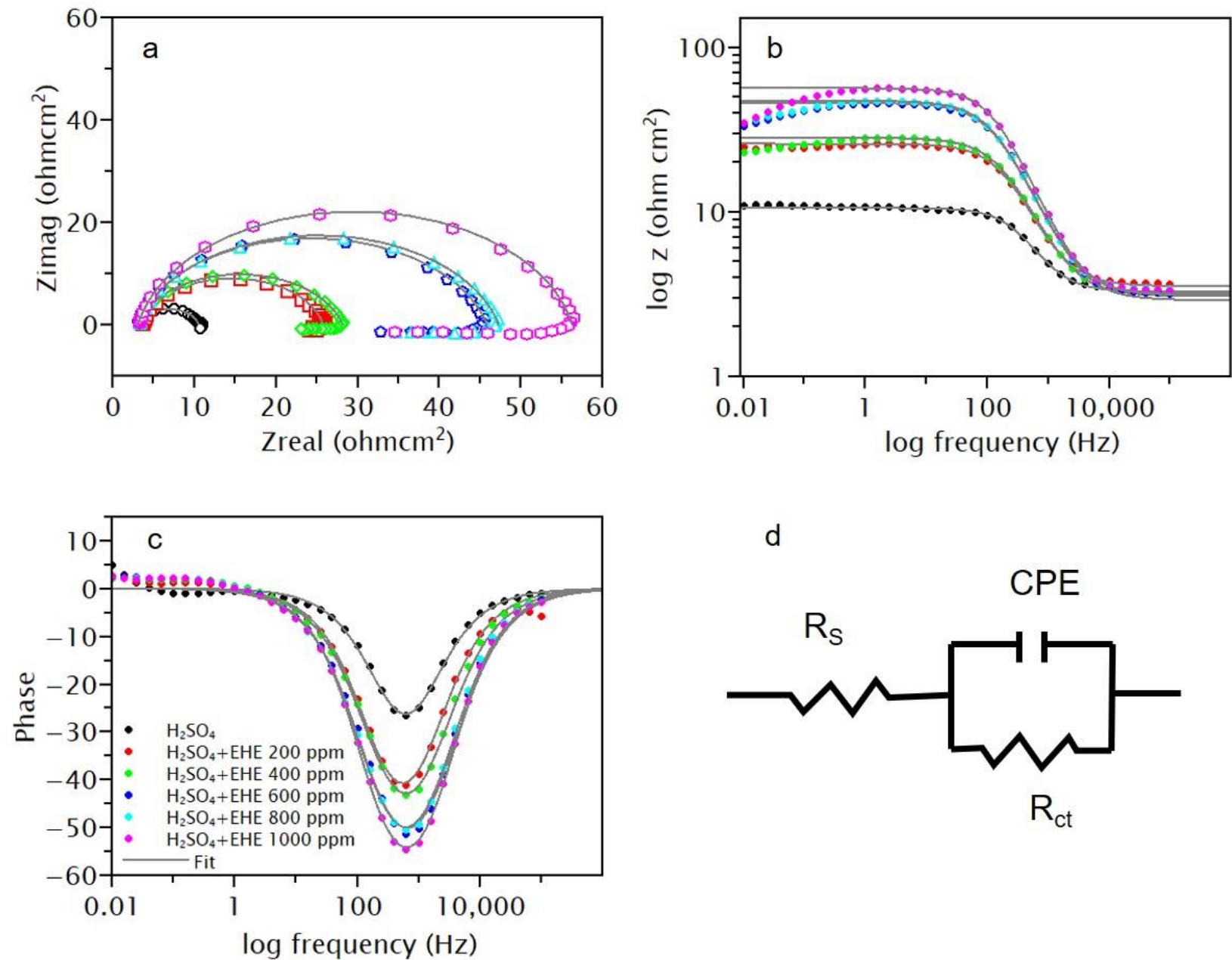

Figure 4. a. Nyquist plots, b. Bode modulus plots of $\log Z$ vs. frequency, c. Bode phase plots of phase angle vs. frequency for mild steel in $1.0 \mathrm{M} \mathrm{H}_{2} \mathrm{SO}_{4}$ with $E H E$ of different concentrations, and d. Equivalent circuit model used to fit the impedance spectra. 


\subsection{Weight Loss Measurement}

Only weight loss measurements can give a real corrosion rate. In weight loss measurements, the effect of longer immersion time up to $24 \mathrm{~h}$ and the effect of concentration of $E H E$ on the inhibition of corrosion of MS sample in acidic solution were studied. The obtained results are compared with the electrochemical data. Figure 5a and 5b depict the weight loss and corresponding $I E$. The results show a significant reduction in weight loss in an acid solution with the addition of the EHE. The $I E$ attains a maximum (82\%) at $6 \mathrm{~h}$ of immersion and decreases to attain a steady value $(70 \%)$ after $12 \mathrm{~h}$ of immersion. The initial increase in $I E$ points to the dissolution of air formed oxide, leading to surface roughening followed by enhanced adsorption of the phytochemicals on the MS surface. The adsorbed phytochemicals blocked the active site of corrosion. However, a decrease of inhibition efficiency after $6 \mathrm{~h}$ of immersion in EHE solution indicated for the gradual desorption of phytochemicals. The chelation of the inhibitor molecules might have promoted desorption with the dissolved $\mathrm{Fe}^{3+}$ or $\mathrm{Fe}^{2+}$ species $[29,57]$. This is essential information concerning the application of such inhibitors in a real application where the time of immersion could be a detrimental factor. On the positive note, the inhibition efficiency after $24 \mathrm{~h}$ of immersion maintained at $70 \%$.
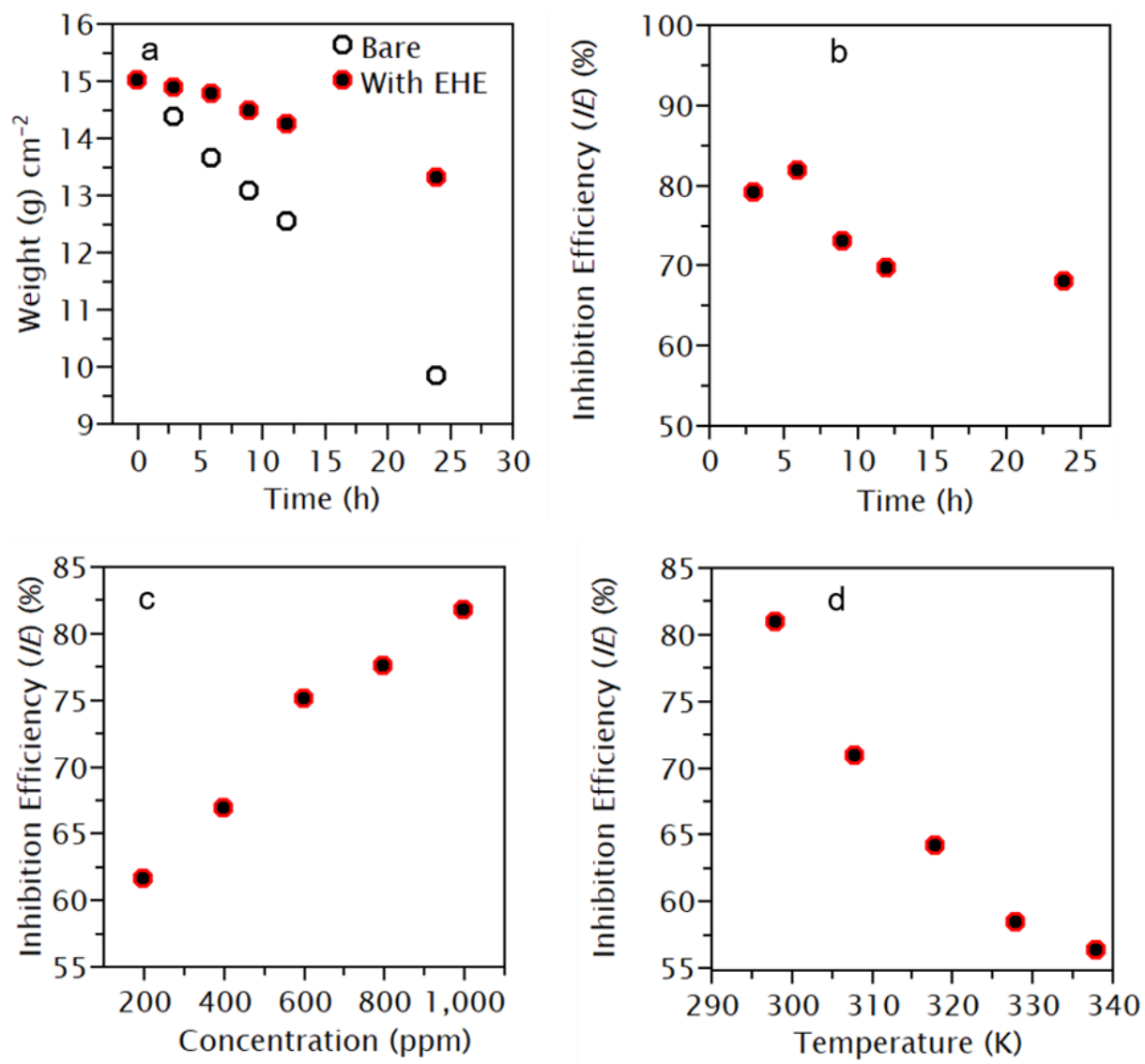

Figure 5. a. Variation in a weight loss of mild steel immersed in $1.0 \mathrm{M} \mathrm{H}_{2} \mathrm{SO}_{4}$ with $E H E$, and inhibition efficiency (IE) of $E H E$ with: b, immersion time; c, concentration; and d, temperature. 
The effect of concentration of $E H E$ on MS corrosion from $200 \mathrm{ppm}$ to $1000 \mathrm{ppm}$ is plotted in Figure 5c. In all these measurements, the immersion time was $6 \mathrm{~h}$ at $298 \mathrm{~K}$. The results reveal an increase in the $I E$ of $E H E$ with concentration. A maximum $I E$ of $82.0 \%$ achieved at $1000 \mathrm{ppm}$ of $E H E$. Accordingly, the surface coverage of MS surface by $E H E$ increased with its concentration due probably to the availability of a large number of inhibitor molecules for adsorption.

The effect of temperature on the adsorption behaviors of the phytochemical of $E H E$ was clarified by weight loss measurement at various temperatures after immersion in 1000 ppm EHE solution for $6 \mathrm{~h}$. The temperature changed from $298 \mathrm{~K}$ to $338 \mathrm{~K}$ at an interval of $10 \mathrm{~K}$, and results are presented in Figure 5d. The results reveal a gradual decrease in $I E$ with temperature. This phenomenon indicates the desorption or decomposition of inhibitor molecules at higher temperatures [61], and such behavior strongly hints at physical adsorption of phytochemicals. The lower adsorption stability of the inhibitor molecules with temperature correlates with the change of $I E$ with time in Figure $5 \mathrm{~b}$.

The inhibition efficiencies estimated by all the three methods are compared in Figure 6. The general features of $I E$ are the same irrespective of the method used to estimate it, and values differed by about $10 \%$ among the three methods is within the range of experimental errors [58].

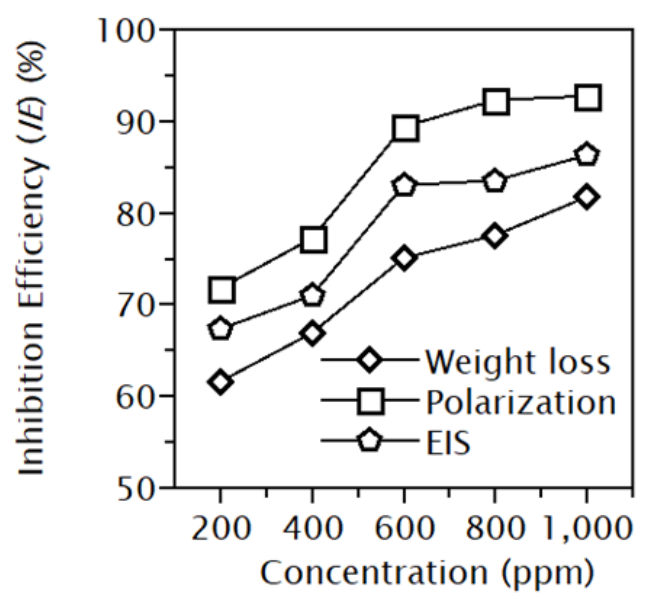

Figure 6. Comparison of variation in inhibition efficiency with the variation of concentration by different methods.

\subsection{Adsorption isotherms}

The inhibition of corrosion by plant extracts is due to the adsorption of phytochemicals on the MS surface [14]. The polar functions of phytochemicals preferentially get adsorbed on a negatively charged metal surface by either physical or chemical interactions or both. The adsorbed phytochemicals function as a barrier for charge and mass transfer between metal and the solution [57]. Therefore, the study of adsorption behavior of inhibitor is an integral part of the study to know about the mode and extent of interaction between the inhibitor and metal surface by evaluating some important thermodynamic parameters such as free energy, 
activation energy, enthalpy and entropy of adsorption. The adsorption of inhibitor molecules can be considered as a quasi-substitution process between the organic molecules of $E H E$ in aqueous phase and pre-adsorbed water dipoles at the MS surface [5, 17, 24].

The adsorption isotherms are determined by working on a linear relation between $\theta$ (surface coverage) value and $C_{\text {inh }}$ (concentration of inhibitor). The testing of various isotherms revealed that the best fit could only be achieved in Langmuir adsorption isotherm

$$
\frac{C_{\mathrm{inh}}}{\theta}=\frac{1}{K_{\mathrm{ads}}}+C_{\mathrm{inh}}
$$

The result is shown in Figure 7a. A linear correlation coefficient $\left(R^{2}=0.9964\right)$ and a slope of 1.1158 are obtained. The adsorption of $E H E$ led to monolayer formation. However, little deviation of slope from unity pointed to some interactions between adsorbed molecules on the MS surface. It may be due to mutual attraction and repulsion between differently adsorbed molecules of different functionalities. In addition, it may also be possible that preferential adsorption of components of the extracts at cathodic and anodic sites took place [30].

$L$-uridine, quercetin, 5 methoxy fulfural, $\alpha$ - $D$-fructofuranose, rutin are a significant component of alcoholic extract of Equisetum hyemale [43]. So, the concentration of EHE is represented here as an average molar concentration of major compounds present in the extract to evaluate the adsorption parameter [32]. Nevertheless, other components present in $E H E$ might also have affected the inhibition behavior of $E H E$.
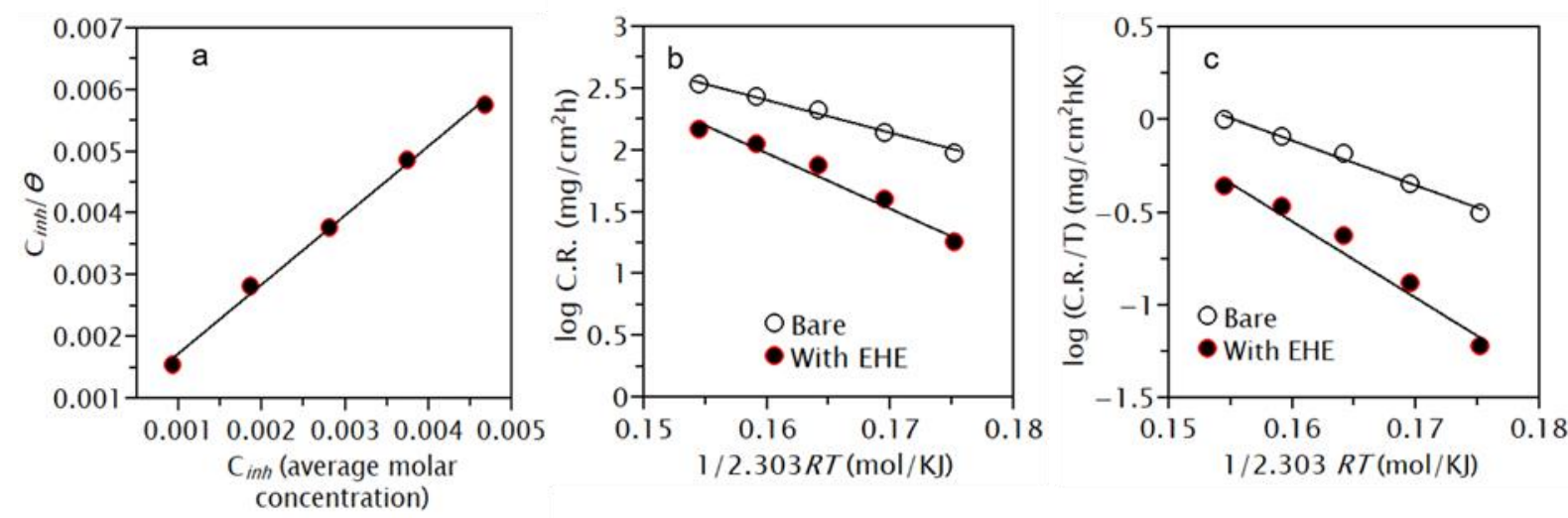

Figure 7. a. Langmuir adsorption isotherm plot for mild steel in $1.0 \mathrm{M} \mathrm{H}_{2} \mathrm{SO}_{4}$ with different concentration of $E H E$ as the average molar concentration of major compounds $b$. Arrhenius plot, and c. Transition state plot for mild steel in $1.0 \mathrm{M} \mathrm{H}_{2} \mathrm{SO}_{4}$ with $E H E$.

From the Langmuir adsorption isotherm plot in Figure 7a, the value of adsorption equilibrium constant ( $K_{\text {ads }}$ ) is obtained from the intercept, which is then used to calculate the standard free energy of adsorption $\left(\Delta G_{\text {ads }}^{0}\right)$ from the equation (8) [17]:

$$
\Delta G_{\mathrm{ads}}^{0}=-R T \operatorname{Ln}\left(55.5 K_{\mathrm{ads}}\right)
$$


Where 55.5 is the molar concentration of water in solution $(\mathrm{mol} / \mathrm{L})$, and $R$ is the universal gas constant $(8.314 \mathrm{~J} / \mathrm{mol} K)$. The substitution of $K_{\text {ads }}$ and other constants values in equation (8) results in $\Delta G_{\text {ads }}^{0}$ of $-28.34 \mathrm{~kJ} / \mathrm{mol}$. The value of $\Delta G_{\text {ads }}^{0}$ indicates that the adsorption of $E H E$ on MS surface is a mixed type involving both physical and chemical interactions a spontaneous manner. It is well known that physical adsorption results in $\Delta G_{\text {ads }}^{0}$ value of less than or equal to $-20 \mathrm{~kJ} / \mathrm{mol}$, while $\Delta G_{\mathrm{ads}}^{0}$ equals to or more than $-40 \mathrm{~kJ} / \mathrm{mol}$ hints to chemical adsorption $[17,57]$. As a matter of fact, an intermediate value of $\Delta G_{\text {ads }}^{0}$ in this study suggests the adsorption process controlled by both interactions of the inhibitors molecules to the MS surface. However, the decrease of $I E$ with temperature in Figure $5 \mathrm{~d}$ contradicts this result of $\Delta G_{\text {ads }}^{0}$ pointing to both physical and chemical adsorptions. It may be assumed that physisorption occurred first due to the electrostatic interaction between charged inhibitor molecules and charged metal surface. Then, thermal agitation energy might be sufficient for desorption of some water dipole, which is reflected by temperature effect, and such a site may be available for chemisorption by charge transfer from organic molecules to the MS surface to form a coordinate type of bond [24]. Nitrogen-containing molecules have a higher potential to share electrons due to the protonation behavior of nitrogen in aqueous solution. The phytochemicals of EHE mostly contain oxygen as the heteroatom, and therefore thermal stability might be weak. Further, the activation energy of the adsorption process is calculated in order to understand the adsorption phenomenon from the relation (9) [26]:

$$
\log (C . R .)=\log A-\frac{E_{\mathrm{a}}}{2.303 R T}
$$

Where C.R. is corrosion rate, $T$ is the absolute temperature, and $A$ is Arrhenius preexponential constant. Table 3 list the calculated values of $E_{\mathrm{a}}$ and $A$, and Figure $7 \mathrm{~b}$ depicts the Arrhenius plot. The increase in the energy barrier in the presence of $E H E$ as inhibitor reflects decrease in corrosion rate.

Furthermore, the change of enthalpy $\left(\Delta H^{*}\right)$ and entropy $\left(\Delta S^{*}\right)$ of activation for the formation of the activation complex in the transition state could be obtained from the transition state equation 10 [26]:

$$
\log \left(\frac{C . R .}{T}\right)=\left[\log \left(\frac{R}{h N}\right)+\left(\frac{\Delta S^{*}}{2.303 R}\right)-\frac{\Delta H^{*}}{2.303 R T}\right]
$$

Where enthalpy of activation $\left(\Delta H^{*}\right)$ is the slope of straight line obtained by plotting $\log (C . R . / T)$ vs. $1 / 2.303 R T$ and entropy of activation $\left(\Delta S^{*}\right)$ can be calculated from the intercept of the line, Figure 7c. In the equation, $h$ is plank's constant, $6.6261 \times 10^{-34} \mathrm{Js}$, and $N$ is the Avogadro's number, $6.0225 \times 10^{23} \mathrm{~mol}^{-1}$. 
Table 3. Activation parameters of the dissolution of mild steel in $1.0 \mathrm{M} \mathrm{H}_{2} \mathrm{SO}_{4}$ containing $1000 \mathrm{ppm} E H E$.

\begin{tabular}{cccccc}
\hline Electrolyte & $\begin{array}{c}\boldsymbol{E}_{\boldsymbol{a}} \\
(\mathbf{k J} / \mathbf{m o l})\end{array}$ & $\begin{array}{c}\text { Constant }(\boldsymbol{A}) \\
\left(\mathbf{m g} / \mathbf{c m}^{2}\right)\end{array}$ & $\begin{array}{c}\Delta \boldsymbol{H} \\
(\mathbf{k J} / \mathbf{m o l})\end{array}$ & $\boldsymbol{E}_{\mathbf{a}}-\Delta \boldsymbol{H}$ & $\begin{array}{c}\Delta S \\
(\mathbf{J} / \mathbf{m o l ~ K})\end{array}$ \\
\hline $1.0 \mathrm{M} \mathrm{H}_{2} \mathrm{SO}_{4}$ & 27.09 & $5.38 \times 10^{6}$ & 24.45 & 2.64 & -124.91 \\
$1.0 \mathrm{M} \mathrm{H}_{2} \mathrm{SO}_{4}+E H E$ & 44.19 & $1.13 \times 10^{9}$ & 41.55 & 2.64 & -80.38 \\
$\left(1000 \mathrm{ppm}^{2}\right)$ & & & & & \\
\hline
\end{tabular}

Calculated values of $\Delta H^{*}$ and $\Delta S^{*}$ for $1.0 \mathrm{M} \mathrm{H}_{2} \mathrm{SO}_{4}$ and $1.0 \mathrm{M} \mathrm{H}_{2} \mathrm{SO}_{4}+1000 \mathrm{ppm}$ of $E H E$ are included in Table 3. A positive value of $\Delta H^{*}$ signifies the endothermic nature of metal-EHE interaction. The value of $\Delta H^{*}$ increases with the addition of $E H E$. This reflects the decrease in the corrosion rate is controlled by kinetic parameters of activation [62]. The value of $E_{\mathrm{a}}$ is higher than that of $\Delta H^{*}$, which implies the involvement of a gaseous reaction, possibly the hydrogen evolution reactions. This leads to a decrease in the total reaction volume [13]. Furthermore, the difference in $E_{\mathrm{a}}-\Delta H^{*}$ value nearly equals to $R T$ shows that the corrosion process is unimolecular. Intermediate values of $E_{\mathrm{a}}$ and $\Delta H^{*}$ reflect a mixed type adsorption of EHE on the MS surface [15, 29,57]. In Table 3, $A$ is the Arrhenius preexponential factor or frequency factor, representing the affinity of ions to get adsorbed on the metal surface. An increase in the value of $A$ in inhibitor solution indicates the higher adsorption affinity of inhibitor molecules to the MS surface. The values of $A$ and $E_{\mathrm{a}}$ are related to each other; therefore an increment of $A$ increases the value of $E_{\mathrm{a}}$ in the inhibitor solution.

As for the value of $\Delta S^{*}$, a significant and negative value in $1.0 \mathrm{M} \mathrm{H}_{2} \mathrm{SO}_{4}$ points to an association step in the rate-determining step. However, the addition of $E H E$ to the acid solution resulted in increasing the $\Delta S^{*}$ value. This may be interpreted as the phenomenon leading to the replacement of water molecules by EHE on metal surfaces. Therefore, cathodic discharge of hydrogen ion is lowered by adsorbed inhibitor molecules, and a more randomly arranged transition state in the rate-determining recombination step is formed [26].

\subsection{Surface analysis}

Energy dispersive $\mathrm{X}$-ray (EDX) was used to get the elemental information of the MS samples immersed in $1.0 \mathrm{M} \mathrm{H}_{2} \mathrm{SO}_{4}$ and $1.0 \mathrm{M} \mathrm{H}_{2} \mathrm{SO}_{4}+E H E$ for $24 \mathrm{~h}$. The EDX spectra are showing the presence of elements C, N, O, P, and Fe in Figure 8. Table 4 shows a decrease of Fe and an increase of $\mathrm{N}$ and $\mathrm{C}$ on the MS surface immersed in an acid solution with EHE. Therefore, the formation of a protective molecular film due to the adsorption of phytochemicals containing $\mathrm{N}, \mathrm{C}$, and $\mathrm{O}$ on the MS surface leads to the inhibition of the Fe dissolution.

In SEM image of MS sample immersed in $1.0 \mathrm{M} \mathrm{H}_{2} \mathrm{SO}_{4}$, there is a severe corrosion attack with deep furrows and large cracks (Figure 8a), whereas MS samples immersed in $1.0 \mathrm{M} \mathrm{H}_{2} \mathrm{SO}_{4}+E H E$ have developed a relatively smooth surface by the adsorption of inhibitor molecules, which form a protective film on MS and inhibits the corrosion attack (Figure $8 \mathrm{~b}$ and $8 \mathrm{c}$ ). 

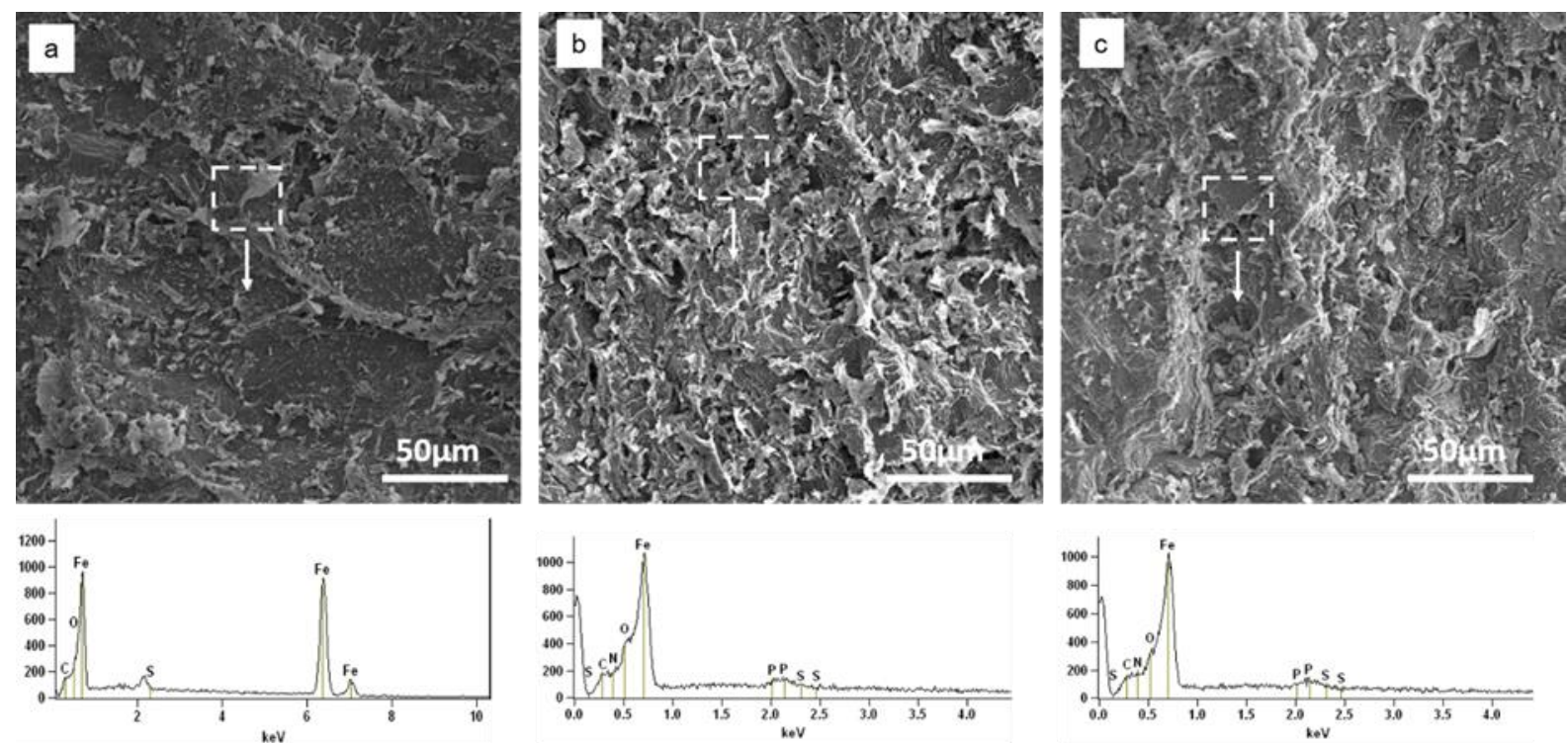

Figure 8. SEM images with corresponding EDX spectra of mild steel sample after $24 \mathrm{~h}$ of immersion in a. $1.0 \mathrm{M} \mathrm{H}_{2} \mathrm{SO}_{4}$ b. $1.0 \mathrm{M} \mathrm{H}_{2} \mathrm{SO}_{4}+400 \mathrm{ppm} E H E$ and c. $1.0 \mathrm{M} \mathrm{H}_{2} \mathrm{SO}_{4}+1000$ ppm $E H E$.

Table 4. Weight of different elements on the MS surface after immersion in the sample in different solutions.

\begin{tabular}{cccccc}
\hline Surface & Iron $(\boldsymbol{\%})$ & $\begin{array}{c}\text { Carbon } \\
(\boldsymbol{\%})\end{array}$ & $\begin{array}{c}\text { Nitrogen } \\
(\boldsymbol{\%})\end{array}$ & $\begin{array}{c}\text { Oxygen } \\
(\boldsymbol{\%})\end{array}$ & $\begin{array}{c}\text { Phosphorus } \\
(\boldsymbol{\%})\end{array}$ \\
\hline Polished metal sample & 100 & - & - & - & - \\
In 1.0 $\mathrm{M} \mathrm{H}_{2} \mathrm{SO}_{4}$ & 97.45 & 1.72 & - & 0.83 & - \\
$1.0 \mathrm{M} \mathrm{H}_{2} \mathrm{SO}_{4}+400 \mathrm{ppm} E H E_{1.0 \mathrm{M} \mathrm{H}_{2} \mathrm{SO}_{4}+1000 \mathrm{ppm} E H E}$ & 92.92 & 1.95 & 1.45 & 3.84 & 0.19 \\
\hline
\end{tabular}

\section{Conclusion}

Extract of stem of Equisetum hyemale acts as a suitable inhibitor for corrosion of mild steel in $1.0 \mathrm{M} \mathrm{H}_{2} \mathrm{SO}_{4}$ solution. Three processes, such as weight loss, thermodynamic parameter, and electrochemical method, are used to calculate the $I E$ of $E H E$. The weight-loss method confirms that the IE of EHE is more than $85 \%$ at $1000 \mathrm{ppm}$. The $I E$ increases with concentration and decreases with temperature increment. IE increases until $6 \mathrm{~h}$, and decreases to maintains a steady-state value after $12 \mathrm{~h}$ of immersion. The thermodynamic parameters calculation also supports the weight-loss results. The adsorption of the extract on the mild steel (MS) follows the Langmuir adsorption isotherm, which indicates the monolayer adsorption of inhibitor on MS surface. The values of $\Delta H^{*}$ and $E_{\mathrm{a}}$ indicate that the adsorption process is spontaneous and endothermic. Electrochemical measurement points out as the inhibition behavior of EHE is a mixed type by showing negligible shift of OCP. 
This result is further supported by only one time constant in EIS. EDX and SEM confirm the suppression of corrosion attack by adsorbed extract on the MS surface.

\section{Acknowledgements}

N. Karki would like to acknowledge the Nepal Academy of Science and Technology for Ph.D. grants. Thanks are due to Prof. V.S. Raja and staff IIT, Bombay for carrying out EIS measurements and surface analysis by SEM-EDX.

\section{Conflicts of interest}

The authors declare no conflicts of interests.

\section{Supplementary material}

The corresponding author provides supplementary material upon a reasonable request.

\section{Reference}

1. NACE International Institute IMPACT PLUS (n.d.), https://www.nace-impact.org/.

2. D. de la Fuente, I. Díaz, J. Simancas, B. Chico and M. Morcillo, Long-term atmospheric corrosion of mild steel, Corros. Sci., 2011, 53, no. 2, 604-617. doi: 10.1016/j.corsci.2010.10.007

3. S.B. Ulaeto, U.J. Ekpe, M. Chidiebere and E.E. Oguzie, Corrosion inhibition of mild steel in hydrochloric acid by acid extracts of eichhornia crassipes, Int. J. Mater. Chem., 2012, 2, 158-164, http://article.sapub.org/10.5923.j.ijmc.20120204.08.html.

4. M.A. Hegazy, A.S. El-Tabei, A.H. Bedair and M.A. Sadeq, Synthesis and inhibitive performance of novel cationic and gemini surfactants on carbon steel corrosion in $0.5 \mathrm{M}$ $\mathrm{H}_{2} \mathrm{SO}_{4}$ solution, $R S C A d v$., 2015, 5, 64633-64650. doi: 10.1039/C5RA06473B

5. M. Murmu, S.K. Saha, N.C. Murmu and P. Banerjee, Effect of stereochemical conformation into the corrosion inhibitive behaviour of double azomethine based Schiff bases on mild steel surface in $1 \mathrm{~mol} \mathrm{~L}-1 \mathrm{HCl}$ medium: An experimental, density functional theory and molecular dynamics simulation study, Corros. Sci., 2019, 146, 134-151. doi: 10.1016/j.corsci.2018.10.002

6. E.E. Oguzie, Y. Li and F.H. Wang, Effect of surface nanocrystallization on corrosion and corrosion inhibition of low carbon steel: Synergistic effect of methionine and iodide ion, Electrochim. Acta, 2007, 52, no. 24, 6988-6996. doi: 10.1016/j.electacta.2007.05.023

7. N.I. Kairi and J. Kassim, The Effect of Temperature on the Corrosion Inhibition of Mild Steel in $1 \mathrm{M} \mathrm{HCl}$ Solution by Curcuma Longa Extract, Int. J. Electrochem. Sci., 2013, 8, 18.

8. A. Aytac, U. Ozmen and M. Kabasakaloglu, Investigation of some Schiff bases as acidic corrosion of alloy AA3102, Mater. Chem. Phys., 2005, 89, no. 1, 176-181. doi: $\underline{10.1016 / j . m a t c h e m p h y s .2004 .09 .003}$ 
9. M. Scendo, The influence of adenine on corrosion of copper in chloride solutions, Corros. Sci., 2008, 50, no. 7, 2070-2077. doi: 10.1016/j.corsci.2008.04.007

10. S. Kertit and B. Hammouti, Corrosion inhibition of iron in $1 \mathrm{M} \mathrm{HCl}$ by 1-phenyl-5mercapto-1,2,3,4-tetrazole, Appl. Surf. Sci., 1996, 93, no. 1, 59-66. doi: 10.1016/01694332(95)00189-1

11. J.M. Roque, T. Pandiyan, J. Cruz and E. García Ochoa, DFT and electrochemical studies of tris(benzimidazole-2-ylmethyl)amine as an efficient corrosion inhibitor for carbon steel surface, Corros. Sci., 2008, 50, no. 3, 614-624. doi: 10.1016/j.corsci.2007.11.012

12. E. Machnikova, K.H. Whitmire and N. Hackerman, Corrosion inhibition of carbon steel in hydrochloric acid by furan derivatives, Electrochim. Acta, 2008, 53, no. 20, 60246032. doi: $10.1016 /$ j.electacta.2008.03.021

13. A. Ostovari, S.M. Hoseinieh, M. Peikari, S.R. Shadizadeh and S.J. Hashemi, Corrosion inhibition of mild steel in $1 \mathrm{M} \mathrm{HCl}$ solution by henna extract: A comparative study of the inhibition by henna and its constituents (Lawsone, Gallic acid, $\alpha-d$-Glucose and Tannic acid), Corros. Sci., 2009, 51, no. 9, 1935-1949. doi: 10.1016/j.corsci.2009.05.024

14. O.L Riggs, Jr and C.C. Nathan, Corrosion Inhibitors, 2nd Edition, Houston, 1973.

15. Y. Li, P. Zhao, Q. Liang and B. Hou, Berberine as a natural source inhibitor for mild steel in $1 \mathrm{M} \mathrm{H}_{2} \mathrm{SO}_{4}$, Appl. Surf. Sci., 2005, 252, no. 5, 1245-1253. doi: 10.1016/j.apsusc.2005.02.094

16. H. Ju, Y. Ju and Y. Li, Berberine as an Environmental-Friendly inhibitor for Hot-Dip coated steels in diluted hydrochloric acid, J. Mater. Sci. Technol., 2012, 28, no. 9, 809816. doi: 10.1016/S1005-0302(12)60135-2

17. I. Ahamad, R. Prasad and M.A. Quraishi, Adsorption and inhibitive properties of some new Mannich bases of Isatin derivatives on corrosion of mild steel in acidic media, Corros. Sci., 2010, 52, no. 4, 1472-1481. doi: 10.1016/j.corsci.2010.01.015

18. M.G. Fontana, Corrosion Engineering, 3rd edition, McGraw-Hill Book Company, New York, 1985.

19. J. K. Odusote, D. O. Owalude, O. Sunday Joseph and R. A. Yahya, Inhibition efficiency of Moringa Oleifera leaf extract on the corrosion of reinforced steel bar in $\mathrm{HCl}$ solution, West Indian J. Eng., 2015, 38, 64-70.

20. A. Mohammadi, S.M.A. Hosseini, M.J. Bahrami and M. Shahidi, Corrosion inhibition of mild steel in acidic solution by apricot gum as a green inhibitor, Prog. Color Color. Coat., 2016, 9, 117-134.

21. P.B. Raja and M.G. Sethuraman, Natural products as corrosion inhibitor for metals in corrosive media A review, Mater. Lett., 2008, 62, no. 1, 113-116. doi: 10.1016/j.matlet.2007.04.079

22. G. Gece, Drugs: A review of promising novel corrosion inhibitors, Corros. Sci., 2011, 53, no. 12, 3873-3898. doi: $\underline{10.1016 / j . c o r s c i .2011 .08 .006}$ 
23. T. Hossein, S. Mehdi and K. Nima, Polarization, EIS and EN studies to evaluate the inhibition effect of vanillin as environment-friendly inhibitor on carbon steel in hydrochloric acid solution, J. Phys. Theor. Chem., 2014, 10, 231-246.

24. H. Cang, Z. Fei, J. Shao, W. Shi and Q. Xu, Corrosion inhibition of mild steel by Aloes extract in HCL solution medium, Int. J. Electrochem. Sci., 2013, 8, 720-734.

25. G. Khan, K.M.S. Newaz, W.J. Basirun, H.B.M. Ali, F.L. Faraj and G.M. Khan, Application of natural product extracts as green corrosion inhibitors for metals and alloys in acid pickling processes- A review, Int. J. Electrochem. Sci., 2015, 10, 6120-6134.

26. A. Hamdy and N.S. El-Gendy, Thermodynamic, adsorption and electrochemical studies for corrosion inhibition of carbon steel by henna extract in acid medium, Egypt. J. Pet., 2013, 22, no. 1, 17-25. doi: 10.1016/j.ejpe.2012.06.002

27. S.A. Umoren, I.B. Obot, A.U. Israel, P.O. Asuquo, M.M. Solomon, U.M. Eduok and A.P. Udoh, Inhibition of mild steel corrosion in acidic medium using coconut coir dust extracted from water and methanol as solvents, J. Ind. Eng. Chem., 2014, 20, no. 5, 3612-3622. doi: $10.1016 /$ j.jiec.2013.12.056

28. L. Bammou, M. Belkhaouda, R. Salghi, O. Benali, A. Zarrouk, H. Zarrok and B. Hammouti, Corrosion inhibition of steel in sulfuric acidic solution by the Chenopodium Ambrosioides extracts, J. Assoc. Arab Univ. Basic Appl. Sci., 2014, 16, no. 1, 8390. doi: 10.1016/j.jaubas.2013.11.001

29. Y. Qiang, S. Zhang, B. Tan and S. Chen, Evaluation of Ginkgo leaf extract as an ecofriendly corrosion inhibitor of X70 steel in $\mathrm{HCl}$ solution, Corros. Sci., 2018, 133, 6-16. doi: $10.1016 /$ j.corsci.2018.01.008

30. N.A. Odewunmi, S.A. Umoren and Z.M. Gasem, Watermelon waste products as green corrosion inhibitors for mild steel in $\mathrm{HCl}$ solution, J. Environ. Chem. Eng., 2015, 3, no. 1, 286-296. doi: 10.1016/j.jece.2014.10.014

31. A.Y. El-Etre, Inhibition of C-steel corrosion in acidic solution using the aqueous extract of zallouh root, Mater. Chem. Phys., 2008, 108, no. 2-3, 278-282. doi: 10.1016/j.matchemphys.2007.09.037

32 A. Tiwari, Y. Uprety and S.K. Rana, Plant endemism in the Nepal Himalayas and phytoge-ographical implications, Plant Divers., 2019, 41, no. 3, 174-182. doi:10.1016/j.pld.2019.04.004

33 N. Karki, Y. Chaudhary, and A.P. Yadav, Thermodynamic, Adsorption and Corrosion Inhibition Studies of Mild Steel by Artemisia vulgaris Extract from Methanol as Green Corrosion Inhibitor in Acid Medium, J. Nepal Chem. Soc., 2018, 39, 76. doi: 10.3126/jncs.v39i0.27041

34. P.R. Shrestha, H.B. Oli, B. Thapa, Y. Chaudhary, D.K. Gupta, A.K. Das, K.B. Nakarmi, S. Singh, N. Karki and A.P. Yadav, Bark extract of Lantana camara in $1 \mathrm{M} \mathrm{HCl}$ as green corrosion inhibitor for mild steel, Eng. J., 2019, 23, 205-211. doi: $\underline{10.4186 / \text { ej.2019.23.4.205 }}$ 
35. B. Thapa, D.K. Gupta and A.P. Yadav, Corrosion inhibition of bark extract of euphobia royleana on mild steel in $1 \mathrm{M} \mathrm{HCl}, J$. Nepal Chem. Soc., 2019, 40, 25-29. doi: 10.3126/jncs.v40i0.27274

36. P.C. Lama, Y. Chaudhary, N. Karki and A.P. Yadav, Study of the corrosion inhibition behavior of pogostemon benghalensis (rudilo) for mild steel in acidic medium by potentiodynamic methodno title, J. Nepal Chem. Soc., 2016, 34, 120.

37. Y. Chaudhary, N. Karki and A.P. Yadav, Study of the corrosion inhibition behavior of Pogostemo benghalensis (Rudilo) for mild steel in acidic medium by weight loss method, J. Nepal Chem. Soc., 2016, 35, 139.

38. R. Lama, A.K. Das, B Yadav, Y. Chaudhary, P.C. Lama, S.L. Shrestha, D.K. Gupta, N. Karki and A.P. Yadav, Corrosion inhibition of mild steel in acidic medium using high altitude plant extract, J. Nepal Chem. Soc., 2018, 38, 48. doi:10.3126/jncs.v38i0.27787

39. N. Karki, S. Neupane, Y. Chaudhary, D.K. Gupta and A.P. Yadav, Berberis aristata: a highly efficient and thermally stable green corrosion inhibitor for mild steel in acidic medium, Anal. Bioanal. Electrochem., 2020, 12, 970.

40. C.F. dos Santos Alves, P.C. Bonez, M. de Souza Ebling, C. Casagrande, L. Freitas, C. Dolwitsch, F. Pires, M.R. Sagrillo, G.F. de Brum, M.M.A. de Campos and R.C. Vianna Santos, Antimicrobial, cyto and genotoxic activities of equisetum hyemale, Pharmacogn. J., 2019, 11, no. 6, 1563-1571. doi: 10.5530/pj.2019.11.239

41. M. Jin, C. Zhang, T. Zheng, D. Yao, L. Shen, J. Luo, Z. Jiang, J. Ma, X.J. Jin, J. Cui, J.J. Lee and G. Li, A new phenyl glycoside from the aerial parts of Equisetum hyemale, Nat. Prod. Res., 2014, 28, 1813-1818. doi: 10.1080/14786419.2014.947491

42. B.J. Park and M. Tomohiko, Feruloyl, caffeoyl, and flavonol glucosides from Equisetum hyemale, Chem. Nat. Compd., 2011, 47, 363. doi: 10.1007/s10600-011-9934-0

43. G. Pandey and S. Khatoon, Evaluation of phytochemical profile and antioxidant activity of equisetum hyemale 1., World J. Pharm. Res., 6-16.

44. C.B. Verma, M.A. Quraishi and A. Singh, 2-Aminobenzene-1,3-dicarbonitriles as green corrosion inhibitor for mild steel in $1 \mathrm{M} \mathrm{HCl}$ : Electrochemical, thermodynamic, surface and quantum chemical investigation, J. Taiwan Inst. Chem. Eng., 2015, 49, 229-239. doi: $\underline{10.1016 / j . j t i c e .2014 .11 .029}$

45. M. Benabdellah, A. Aouniti, A. Dafali, B. Hammouti, M. Benkaddour, A. Yahyi and A. Ettouhami, Investigation of the inhibitive effect of triphenyltin 2-thiophe-ne carboxylate on corrosion of steel in $2 \mathrm{M} \mathrm{H}_{3} \mathrm{PO}_{4}$ solutions, Appl. Surf. Sci., 2006, 252, no. 23, 8341-8347. doi: 10.1016/J.APSUSC.2005.11.037

46. C.M. Fernandes, L.X. Alvarez, N.E. dos Santos, A.C. Maldonado Barrios and E.A. Ponzio, Green synthesis of 1-benzyl-4-phenyl-1H-1,2,3-triazole, its application as corrosion inhibitor for mild steel in acidic medium and new approach of classical electrochemical analyses, Corros. Sci., 2019, 149, 185-194. doi: $\underline{10.1016 / j . c o r s c i .2019 .01 .019}$ 
47. K. Jüttner, Electrochemical impedance spectroscopy (EIS) of corrosion processes on inhomogeneous surfaces, Electrochim. Acta, 1990, 35, no. 10, 1501-1508. doi: $\underline{10.1016 / 0013-4686(90) 80004-8}$

48. M. Hosseini, S.F.L. Mertens, M. Ghorbani and M.R. Arshadi, Asymmetrical Schiff bases as inhibitors of mild steel corrosion in sulphuric acid media, Mater. Chem. Phys., 2003, 78, no. 3, 800-808. doi: 10.1016/S0254-0584(02)00390-5

49. F. Bentiss, M. Traisnel and M. Lagrenee, The substituted 1,3,4-oxadiazoles: a new class of corrosion inhibitors of mild steel in acidic media, Corros. Sci., 2000, 42, no. 1, $127-$ 146. doi: 10.1016/S0010-938X(99)00049-9

50. S. Shahabi, P. Norouzi and M.R. Ganjali, Theoretical and electrochemical study of carbon steel corrosion inhibition in the presence of two synthesized Schiff base inhibitors: Application of fast Fourier transform continuous cyclic voltammetry to study the adsorption behavior, Int. J. Electrochem. Sci., 2015, 10, 2646-2662.

51. A.O. Yüce and G. Kardaş, Adsorption and inhibition effect of 2-thiohydantoin on mild steel corrosion in $0.1 \mathrm{MHCl}$, Corros. Sci., 2012, 58, 86-94. doi: 10.1016/j.corsci.2012.01.013

52. Q. Ma, S. Qi, X. He, Y. Tang and G. Lu, 1,2,3-Triazole derivatives as corrosion inhibitors for mild steel in acidic medium: Experimental and computational chemistry studies, Corros. Sci., 2017, 129, 91-101. doi: 10.1016/j.corsci.2017.09.025

53. M.A. Bedair, M.M.B. El-Sabbah, A.S. Fouda and H.M. Elaryian, Synthesis, electrochemical and quantum chemical studies of some prepared surfactants based on azodye and Schiff base as corrosion inhibitors for steel in acid medium, Corros. Sci., 2017, 128, 54-72. doi: $10.1016 / \mathrm{j}$. corsci.2017.09.016

54. M.A. Veloz and I. González, Electrochemical study of carbon steel corrosion in buffered acetic acid solutions with chlorides and $\mathrm{H}_{2} \mathrm{~S}$, Electrochim. Acta, 2002, 48, no. 2, 135-

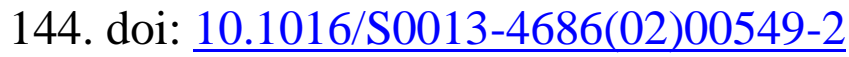

55. M.A. Hegazy, M. Abdallah, M.K. Awad, M. Rezk, Three novel di-quaternary ammonium salts as corrosion inhibitors for API X65 steel pipeline in acidic solution. Part I: Experimental results, Corros. Sci., 2014, 81, 54-64. doi: 10.1016/J.CORSCI.2013.12.010

56. B. Xu, W. Yang, Y. Liu, X. Yin, W. Gong and Y. Chen, Experimental and theoretical evaluation of two pyridinecarboxaldehyde thiosemicarbazone compounds as corrosion inhibitors for mild steel in hydrochloric acid solution, Corros. Sci., 2014, 78, 260-268. doi: 10.1016/J.CORSCI.2013.10.007

57. R. Sadeghi Erami, M. Amirnasr, S. Meghdadi, M. Talebian, H. Farrokhpour, K. Raeissi, Carboxamide derivatives as new corrosion inhibitors for mild steel protection in hydrochloric acid solution, Corros. Sci., 2019, 151, 190-197. doi: 10.1016/j.corsci.2019.02.019

58. P. Mourya, S. Banerjee and M.M. Singh, Corrosion inhibition of mild steel in acidic solution by Tagetes erecta (Marigold flower) extract as a green inhibitor, Corros. Sci., 2014, 85, 352-363. doi: 10.1016/j.corsci.2014.04.036 
59. F. Bentiss, M. Lagrenee, M. Traisnel and J.C. Hornez, The corrosion inhibition of mild steel in acidic media by a new triazole derivative, Corros. Sci., 1999, 41, no. 4, 789803. doi: 10.1016/S0010-938X(98)00153-X

60. M.A. Quraishi and F.A. Ansari, Corrosion inhibition by fatty acid triazoles for mild steel in formic acid, J. Appl. Electrochem., 2003, 33, 233-238. doi: 10.1023/A:1024106123577

61. F. Bentiss, M. Lebrini, H. Vezin, F. Chai, M. Traisnel and M. Lagrené, Enhanced corrosion resistance of carbon steel in normal sulfuric acid medium by some macrocyclic polyether compounds containing a 1,3,4-thiadiazole moiety: AC impedance and computational studies, Corros. Sci., 2009, 51, no. 9, 2165-2173. doi: 10.1016/J.CORSCI.2009.05.049

62. J.I. Bhat, D.P. Vijaya, V. Alva, Meclizine hydrochloride as a potential non-toxic corrosion inhibitor for mild steel in hydrochloric acid medium, Arch. Appl. Sci. Res., $2011,3,343$. 